\title{
GLL
}

Geomatics, Landmanagement and Landscape No. $3 \cdot 2021,7-23$

\section{DETERMINING THE VOLUME OF SOIL MASSES USING DIFFERENT MEASUREMENT TECHNIQUES}

\author{
Bogusława Kwoczyńska
}

\begin{abstract}
Summary
Calculating the volume for various types of surfaces and materials is important for many branches of engineering sciences. Correct volume calculation often has a significant impact on the cost and time of a given project. These type of calculations are already applied at the design level. Measurement of cubature is crucial, for example, in construction and mining.

The paper presents an analysis of and calculation results for measuring the volume of soil masses using different measurement techniques, which include: LIDAR (in this case of terrestrial and airborne laser scanning), photos taken with the use of UAV and measurements in the GNSS method. The object of the study was an earth mound located in the Park Dębnicki in Kraków. Relative volume error has been calculated in relation to the terrestrial laser scanning (TLS) method. For each of the tested methods, the error remained within the limits allowed by the standards and amounted to $0.2 \%$ for airborne laser scanning (ALS), 2.3\% for photos obtained from UAVs and 3.4\% for the GNNS-RTK method. The results of tests are presented in graphic and tabular forms. The obtained results were compared and the most advantageous measurement techniques to be used in determining the cubic capacity of this particular research object was indicated.
\end{abstract}

\section{Keywords}

volume • soil mass • LIDAR • UAV

\section{Introduction}

Measuring the volume of soil masses is very important for many branches of engineering sciences, such as construction and mining. Professional soil mass measurements are indispensable for construction works, as well as road and railway investments. In the case of excavations for the foundations of buildings or roads, soil mass measurements allow for rational management of the obtained soil. After measuring the soil masses and measuring the planned excavations, it becomes possible to balance these soil masses without the need to transport soil from outside the investment area. Such actions have a major impact on planning of the investment costs, at the same time allowing to save significant funds. 
Choosing the right method for measuring the volume of soil masses, as well as professional preparation of these measurements and the correct settlement of the construction investment by a specialized company, often allows for the reduction of unnecessary costs, which in turn translates into significant savings in the implementation of the investment.

Soil mass measurement methods are also used to measure mining and metallurgical waste stored in mine tips. Measurement of mining and metallurgical waste allows to determine the storage status of this aggregate and to plan the disposal of waste for its use, e.g. in road construction or in building construction.

Over the last dozen or so years, a significant development of techniques for acquiring measurement data in the field of photogrammetry has been observed. Laser scanning has become a very dynamically developing part of photogrammetry, which for nearly thirty years has increased its range and is used for many purposes in geodesy and in other fields. This is connected to increasing speed of obtaining large amounts of data, high measurement accuracy, greater independence from weather conditions and more convenient way of measuring difficult terrain than using other methods. This technology allows to take static and mobile measurements both on the ground surface and in the air. The emergence of devices capable of collecting large amounts of numerical data in the form of coordinates has resulted in new methods of analysis and processing of data. Based on this data, it is possible to quickly obtain numerical terrain models and digital land cover models that give many opportunities for their use.

Using a digital terrain model, it is possible to obtain fully three-dimensional models, which serve as electronic data set on the terrain, existing infrastructure elements, vegetation cover, etc. The full metricity of such a model with a dedicated software allows to measure the volume of soil masses, determine the distances to existing objects, delineate surfaces, generate cross-sections. Thanks to all these elements, a whole three-dimensional environment can be created that will perfectly represent the area and enable further design.

Another important field in geodesy and cartography, where numerical terrain models are commonly used, is measuring the volume of coal, aggregates, ores, ashes, humus and other loose raw materials, performed for companies with warehouses in the form of tips and piles, or conducting mining activities.

The numerical terrain model (NMT) accurately represents the shape of the stored raw materials and is used to perform volume calculations. Measuring the volume of coal or other aggregates allows to determine stock levels or assess the progress of mining. For these applications, the speed of measurement and high precision of the mapping of the terrain surface are particularly important. The aim of these operations is not only quick calculation of the quantity and the assessment of condition of a given raw material, but also to minimise any possible losses caused by improper densification. This is all the more important the greater the daily turnover of the material of a given enterprise. A lot of income can be saved thanks to results from such measurements. Also, the exact state of the inventory can be identified, which allows for better planning of material distribution. 
The fastest growing data acquisition technology on this market is photogrammetry, implemented by drones. It ensures a very fast measurement process, without disrupting production processes. It optimises the process in economic terms and increases safety while taking measurements. It does not require manual operation of an entire team, but only a trained drone operator who surveys the area with specialized models of these devices. This not only saves time, money and the stress associated with possible corrections, but also guarantees a much higher quality of the measurements obtained. Drones are a modern solution that gives exceptionally spectacular results in geodesy, which is proven by a professional and wide use of the terrain model.

In this paper, it was decided to take a closer look at four currently most popular cubic surveying methods and conduct own research, which would allow to show the greatest benefits and disadvantages of each method in this type of geodesy surveying work. The results of calculations of the soil mass volume were compared on the basis of data obtained from airborne and terrestrial laser scanning, images from UAV (Unmanned Aerial Vehicle) and GNSS measurement.

\section{Research site}

The measured object was a mound located in the Dębnicki Park on Praska Street in Kraków, in the Dębniki district. The mound is an earthwork in the shape of a truncated cone with a diameter of about $20 \mathrm{~m}$ and height of about $5 \mathrm{~m}$ (Fig. 1). It was selected for measurements for its simple shape, its relatively small dimensions for this type of object and the lack of vegetation in its proximity to interfere with the measurements.

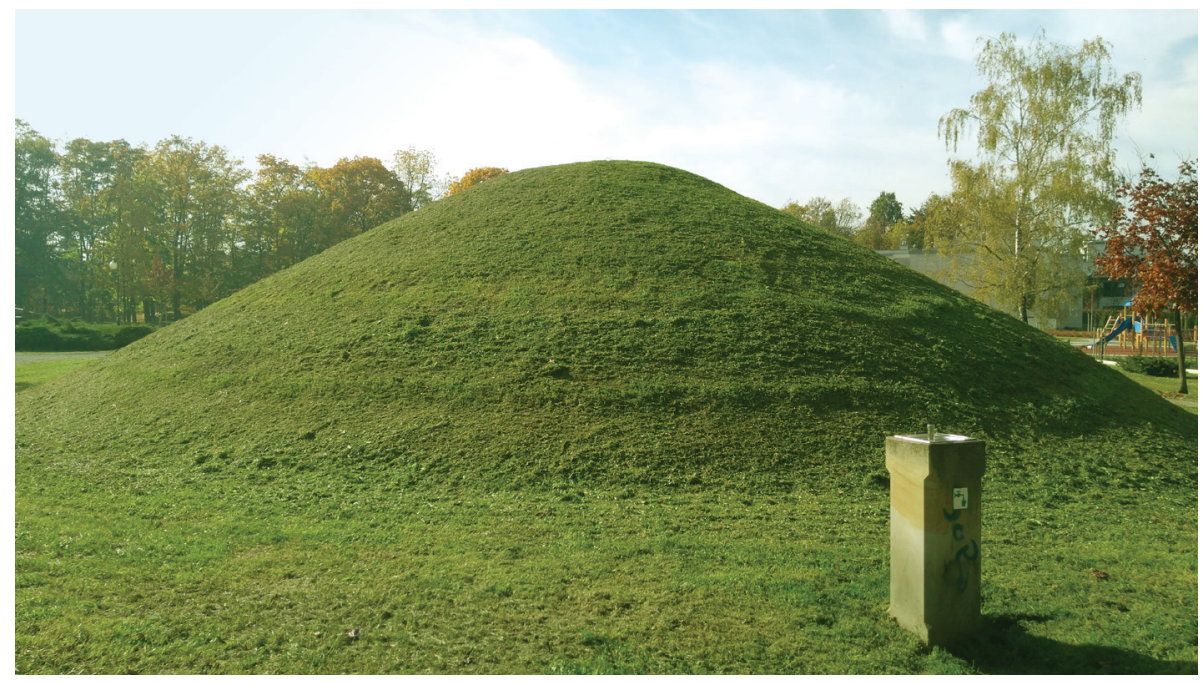

Photo: B. Kwoczyńska

Fig. 1. The mound from the east 


\section{Methods of measurement of the volume of soil masses}

The choice of field measurement method depends on many factors, which are determined by the type and extent of the area and the availability of measurement equipment. In engineering practice, a distinction is made between the following field measurement methods used to calculate the volume of soil masses:

- mesh levelling method,

- scattered point method,

- method of levelling longitudinal and transverse cross-sections,

- tacheometry,

- RTK - GPS (Real Time Kinematic - Global Position System) method,

- radar interferometry method,

- laser scanning method.

Currently, the most popular and effective methods of calculating the masses of the earth's surface include the following methods: Global Position System, photogrammetric and laser scanning method. It is known from experience that the results of measurements carried out with these methods are the most accurate and, importantly, the person performing these measurements has no influence on the result of a test.

Currently, it is possible to obtain geospatial data that represent the terrain surfaces in the form of a point cloud, using two diametrically different technologies: laser scanning and 'structure from motion' - a technology based on blocks of correctly acquired $2 \mathrm{D}$ photos. Both of these technologies allow to obtain essentially the same outcome - point clouds, although it is an outcome of direct measurement from laser scanning technology (ALS and TLS), while in the case of structures from motion technology it is an outcome derived from source data such as processed photos [Mitka et al. 2018].

The research included three of the above-mentioned measurement techniques, i.e. airborne and terrestrial laser scanning and the RTK-GPS method, which were compared with the fourth method - the use of UAVs.

\subsection{Laser scanning}

Laser scanning, called LIDAR (Light Detection and Ranging), is currently one of the fastest and the most practical technologies for obtaining data on various types of objects. Due to the fact that this method enables remote testing with the use of low-infrared radiation, it is classified as an active remote sensing method. Infrared bands mean that the method does not depend on lighting conditions. The result of tests with the laser scanning is a set of points, the position of which can be determined by measuring horizontal angles, vertical angles and distances. Based on these values, it is possible to calculate the XYZ coordinates of cloud points [Wężyk 2006].

Depending on the location of the scanner, this technology can be divided into aerial laser scanning (SLS - Satellite Laser Scanning, and airborne ALS - Airborne Laser 
Scanning) and terrestrial laser scanning (mobile - MLS - Mobile Laser Scanning, and static - TLS - Terrestrial Laser Scanning).

In the case of this study, both aerial and terrestrial laser scanning were used to obtain the volume of soil masses.

\subsubsection{Terrestrial laser scanning}

Terrestrial laser scanners (TLSs) are electronic total stations that perform a reflectorless distance measurement. The basic model of a terrestrial laser scanner consists of a transmitter, rotating mirrors, optical telescope, detector and recorder. The transmitter produces a laser beam that reaches a system of rotating mirrors [Quintero et al. 2008]. The rotating mirrors guarantee a precise distribution of the laser beam over the surface of the object in an appropriate resolution. As to the measuring device, the laser beam is focused through the optical telescope and passes through a detector, which task is to convert the light energy into a pulse recorded in the recorder module [Quintero et al. 2008, Klapa and Mitka 2017]. Terrestrial laser scanners, often in combination with other measurement techniques, are perfect devices for studying surface topography, monitoring landslides and land deformations, geomorphic processes, or calculating the volume of mass destruction forms [Wójcik et al. 2018].

They are used to monitor landslides [Barbarella et al. 2015], cliffs [Janowski et al. 2014], or - in combination with other measurement methods - to study mass movements in mountain areas [Kenner et al. 2014]. This technology is also used for precise terrain modelling and quantitative assessment of spatial and temporal transformations in the polar environment [Kociuba et al. 2014]. Terrestrial laser scanners are increasingly used to measure the volume of soil masses, especially where dynamic changes occur, where high measurement accuracy is required and when access to the measured area is limited [Wójcik et al. 2018].

\subsubsection{Airborne laser scanning}

Airborne laser scanning (ALS), just like terrestrial laser scanning, measures with a lowinfrared light beam, called NIR (Near Infra Red), although there are also instruments that use green light (bathymetric scanners). A significant difference, when compared to the terrestrial type, is its lower accuracy, which in this case drops from a few to several millimetres [Pilecki 2012]. The ALS technology uses a helicopter or an aeroplane for transport. Helicopters are more expensive to operate, but they are used for research that requires higher accuracy, ranging from about 3-4 to 30-40 scanned points per $1 \mathrm{~m}^{2}$. Aeroplanes offer a cloud density of 1-2 to 3 points per $1 \mathrm{~m}^{2}$, therefore they are used to scan larger areas than helicopters [Wężyk 2006].

The technology of airborne laser scanning continues to strengthen its position and represents an increasingly compelling alternative to other methods (e.g. aerial photogrammetry, radar imaging) providing 3D data needed for various kinds of research. Therefore, this technology is constantly evolving, especially when it comes to implementing new technological solutions, such as constructing new scanning systems, or placing them on new types of vehicles, such as unmanned aerial vehicles - UAVs. 


\subsection{UAV}

One of the methods of measuring the cubature of objects is the unmanned aerial vehicle (UAV) serving as a carrier for a device with a photogrammetric technology. Measuring large objects is extremely important for the following fields: soil erosion analysis, landslide measurement and analysis, reclamation of post-mining areas (e.g. reclamation of tips), design of large earth objects (canal walls, embankments, etc.) [Tang et al. 2014].

Unmanned Aerial Vehicle has the unique ability to quickly explore a vast area and acquire high-resolution images [McGonigle et al. 2008]. According to Wójcik et al. [2019], UAVs have great potential for commercial, scientific and research applications, and the use of professional civilian UAVs around the world is growing rapidly. UAVs help in providing spatial data for civil engineering, mining, GIS, geology, construction and many others [Figueira et al. 2015]. Thanks to the almost unlimited possibility of collecting information, UAVs have also found a number of applications in surveying, cartography, archaeology, cultural heritage, technical and architectural documentation, modelling of buildings, monuments and landscape [Eisenbeiss and Sauerbier 2011]. Such a wide range of applications is due to the fact that UAVs can have different types of construction (e.g. micro-helicopter, helicopter, rotary-wing UAV, quadrotor, multirotor, drone, etc.), shape and size [Tang et al. 2013, Xu et al. 2014]. Research on the use of drones for studying landslides and mass waste is constantly being conducted [Eisenbeiss and Sauerbier 2011, Tang et al. 2013, Xu et al. 2014]. UAVs are more and more often used in civil engineering and mining for inventorying large industrial areas, i.e. open-cast mines, quarries, gravel pits and all kinds of facilities that require constant monitoring and control [Wójcik et al. 2019]. UAVs ensure fast and accurate mapping of large areas, calculations of volume of scanned (measured) objects [Raeva et al. 2016, Xiang et al. 2018], and creating a numerical 3D model from the acquired point cloud [Shahbazi et al. 2015].

\subsection{GNNS}

GNSS (Global Navigation Satellite Systems) is a satellite positioning system that currently plays one of the main roles in geodesy. Initially, it was used by the army, but since then it found many applications in the civil industry, including geodesy. The first satellite guidance systems were developed in the 1970s. They are used to determine the position of users with a receiver. The systems consist of a cosmic space segment, a user segment and a control segment. The space segment consists of satellites orbiting the Earth in medium orbits. The control system includes ground stations that monitor the space system [Kwinta and Szeptalin 2010].

The principle of positioning systems is to know the coordinates of the satellites at the time the signal is sent and to measure the pseudo-distance from the satellite to the receiver.

The test object was measured with the RTK (Real Time Kinematic) method, where corrections to the receiver's position are determined in real time on the basis of data 
sent by the base station. Observations made by GNSS receivers are often affected by errors (mainly atmospheric), and have limited accuracy.

The receiver that calculates the measurement corrections and then sends these corrections via radio waves or GMS is called the reference station or the base receiver. The RTK method gives the best results if the distance between the receiver and the reference station is relatively short - maximum of 35-40 km. Errors in GNSS measurements mainly stem from atmospheric conditions and are characterized by the fact that over a certain area their errors are so small that they have little effect on the accuracy of measurements. In the RTK measurement receiver, the receiver of the GNSS observation corrections is able to improve the accuracy to a few centimetres.

\section{Measurements and test results}

Points of the local measurement network were used to measure the volume of the mound. Stands with Leica discs were placed above the points of the network, thanks to which it was possible at a later stage of the works to orientate the point cloud in the selected reference system, as well as to transform the coordinates to the 1992 system. Measurement by terrestrial laser scanning was performed with the Leica P40 laser scanner (Fig. 2) from six positions.

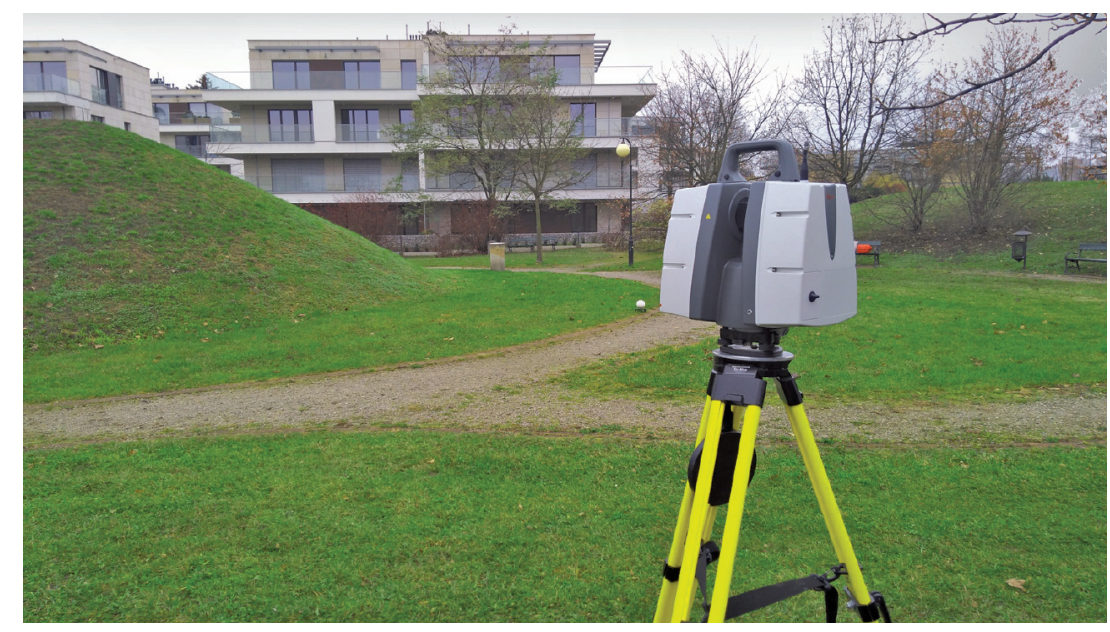

Photo: B. Kwoczyńska

Fig. 2. Leica P40 scanner during the mound scanning

The measurements were also made by the FLY - TECH DJI S1000 octopter drone with a Sony ILCE-7R digital camera equipped with a $35 \mathrm{~mm}$ fixed lens (Fig. 3). The field work involved obtaining geospatial data from low-level aerial imagery and laser scanned point clouds. 


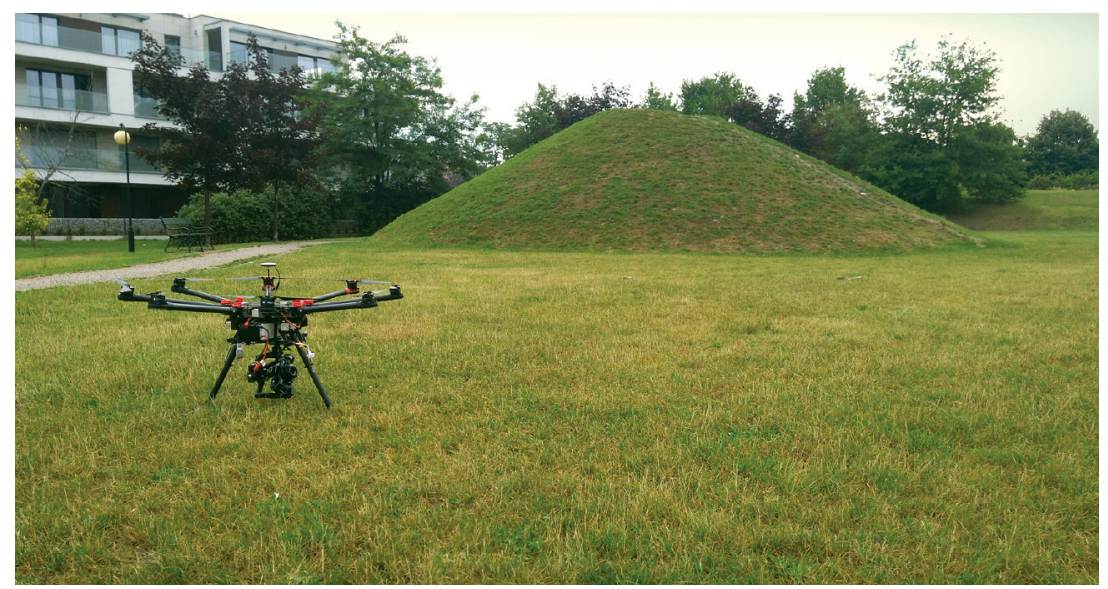

Photo: B. Kwoczyńska

Fig. 3. FLY - TECH DJI S 1000 drone

Before the field raid, 8 photopoints were placed in the form of black and white square targets with dimensions of $10 \times 10 \mathrm{~cm}$. The targets were measured by the GNSS receiver in the same way as the network points. As a result of the measurement, the XYH coordinates in the 2000 system were obtained.

The third of the methods applied directly in the field to measure the mound used a Trimble R8-3 GNSS receiver. The points of the local control network were measured here (3-minute interval) in two series - the first before measuring the mound and the second, after measuring the pickets on the mound. In addition to the network, 125 pickets were measured, of which 119 points were on the mound and 7 points next to it. The measurement of the test object was made using the RTK method, where corrections to the receiver's position are determined in real time on the basis of data sent by the base station. The used ASG-EUPOS patch stream is RTCM 3. All pickets were measured with the receiver with the antenna set at a height of $2 \mathrm{~m}$.

\subsection{Calculation of the volume of soil masses}

The data on the basis of which the calculation of the volume of soil masses was performed were originally in the following three coordinate systems:

- Aerial scanning - 1992 system,

- GNSS measurement - 2000 system,

- Terrestrial scanning - local system,

- Drone raid - 2000 system.

Therefore, before performing volume calculations, data from terrestrial scanning and GNSS measurements were transformed to a system in which there was a point 
cloud from aerial laser scanning, i.e. to the 1992 system. This system was chosen because it was much more convenient to transform several hundred points measured with a GNSS receiver than with aerial scanning, which is much more dense. Also, the txt format of the GNSS measurement facilitated the transformation of points. Due to the fact that the data from the terrestrial scanning were in the local system, they could be transformed to any system and did not affect the choice of the reference system.

\subsubsection{Development of data from terrestrial scanning measurement}

Reference spheres were used to orient the point clouds, and the average error of the entire registration was $0.006 \mathrm{~m}$. During office works, the point cloud was cleaned, which meant removing its unnecessary elements, leaving only the mound and a fragment of the area in its vicinity. The most important fragment of the cloud to be cleaned was the fragment directly above the mound, since inaccurate cleaning of this part could affect the result of the volume calculations. Cleaning the point cloud (Fig. 4) also reduces the size of the visible cloud, which had a positive effect on other subsequent studies that used this cloud.

The calculation of the volume was carried out in the Cyclone program, which allows to calculate the volume in several ways. In this case, it was decided to calculate the volume of the mound from the ground level from a point located in its vicinity, and determined during the measurement with a GNSS receiver. On the basis of the point cloud, a mesh was created (a surface model using a triangle grid), which gave the result of the volume of soil mass $-486.9 \mathrm{~m}^{3}$.

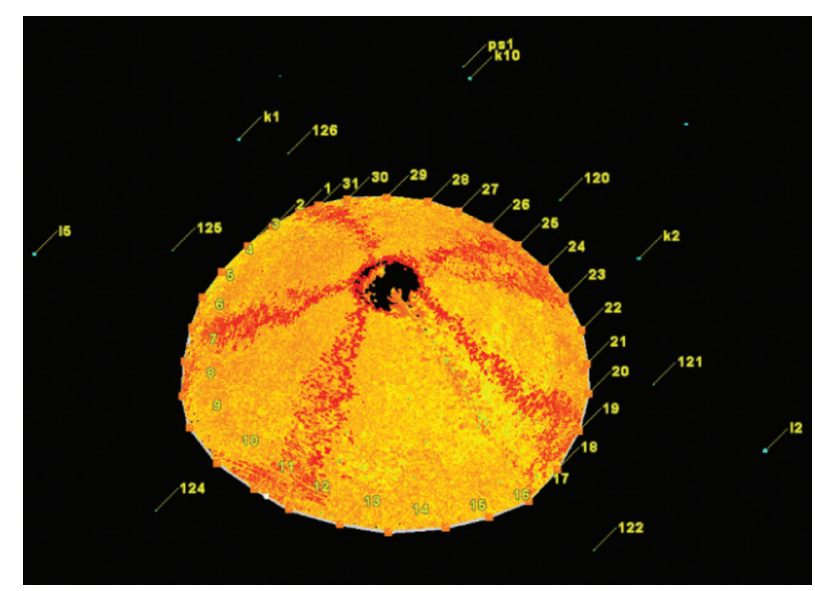

Source: Author's own study

Fig. 4. A fragment of a cut out point cloud with a mound

4.1.2. Development of the aerial scanning method data

The volume calculation based on ALS data involved a classified fragment of a point cloud obtained from the Main Centre for Geodesic and Cartographic Documentation 
(CODGiK). The point cloud fragment was recorded in a LAZ file, contained 5,968,141 points and was adjusted to the 1992 coordinate system. The point cloud was classified automatically, which means that individual points were assigned to the appropriate classes. The density of the point cloud was $12 \mathrm{pts} / \mathrm{m}^{2}$. The volume calculation was made in TerraSolid, in the TerraModeler module running in a MicroStation environment. This module allows to visualise the model, for example in the form of a TIN model which presents height (Fig. 5) or slope of the terrain in colour, or to create hypsometric layers including their slopes, as well as to display various types of hypsometric layers and their description.

The obtained volume was $487.9 \mathrm{~m}^{3}$, which is $1.0 \mathrm{~m}^{3}$ greater than the volume calculated from data from terrestrial laser scanning.

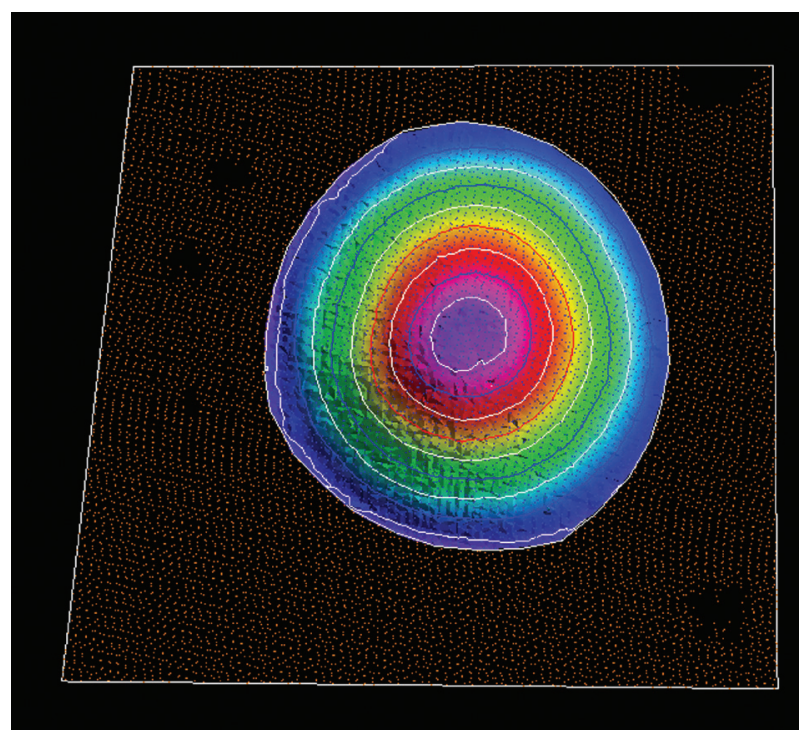

Source: Author's own study

Fig. 5. Model of the mound presented in colour form with hypsometric layers

\subsubsection{Development of GNNS measurement data}

The calculation of the mound volume based on the data measured by the GNSS receiver (Fig. 6) was performed in the C-GEO program, version 8.11.03. It is a program that is used for many geodetic tasks, e.g. levelling calculations, total stations, polygon strings, azimuths, as well as creating maps, cross-sections, sketches and many others.

Two lower and upper NMT models were created for calculating the volume of the mound (Fig. 7). The calculated volume was $503.4 \mathrm{~m}^{3}$. 


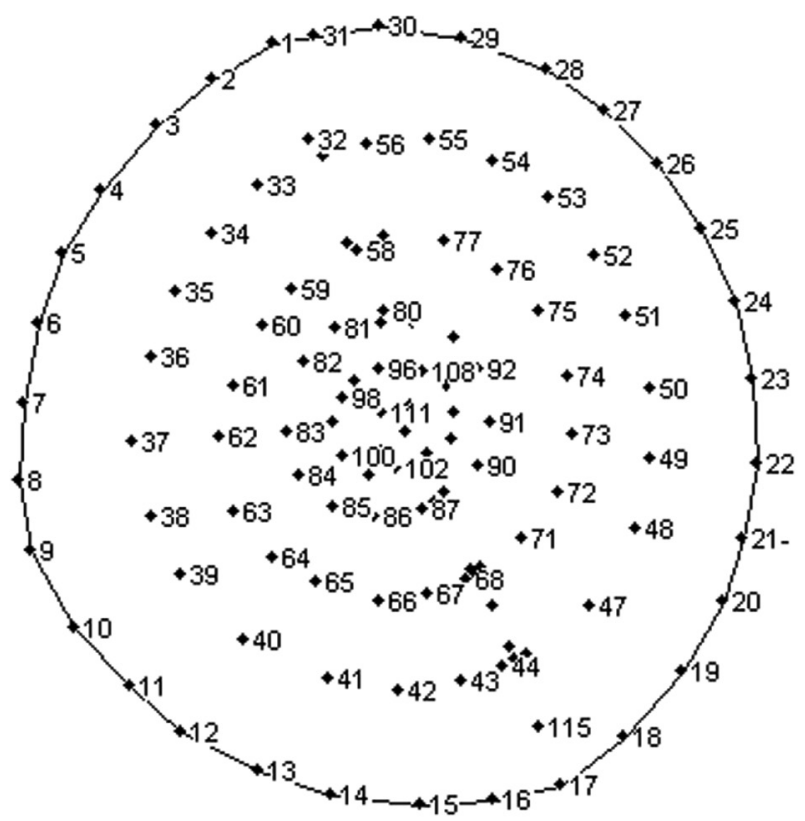

Fig. 6. Sketch of points and outline of the mound

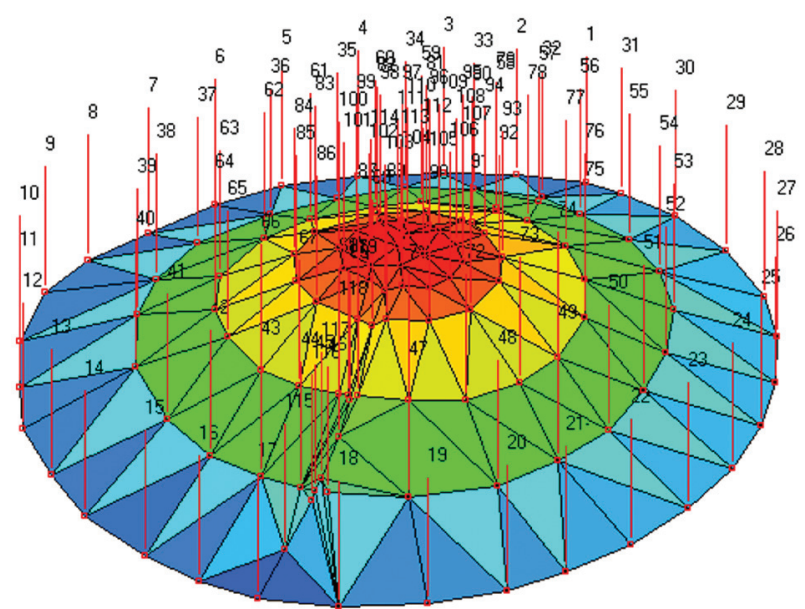

Fig. 7. NMT top model with numbering the points in C-GEO program

\subsubsection{Development of UAV measurement data}

The processed photos were the basis for developing 3D models in the Agisoft Metashape program. Adjacent images were combined into blocks, and photo orientation required loading the coordinates of photopoints in the selected 1992 reference system. The 
photopoints were recorded in the photos. As a result of aligning the block of photos, the average error was $0.02 \mathrm{~m}$. A dense point cloud was generated (Fig. 8), exported and then loaded into TerraSolid. The further steps were analogous to those of calculating the volume of the mound on the basis of LIDAR data. Numerical terrain models with the same names as classes were created (Fig. 9). The volumes between the newly created models in the TerraModeler overlay were calculated with a result of $498.2 \mathrm{~m}^{3}$.

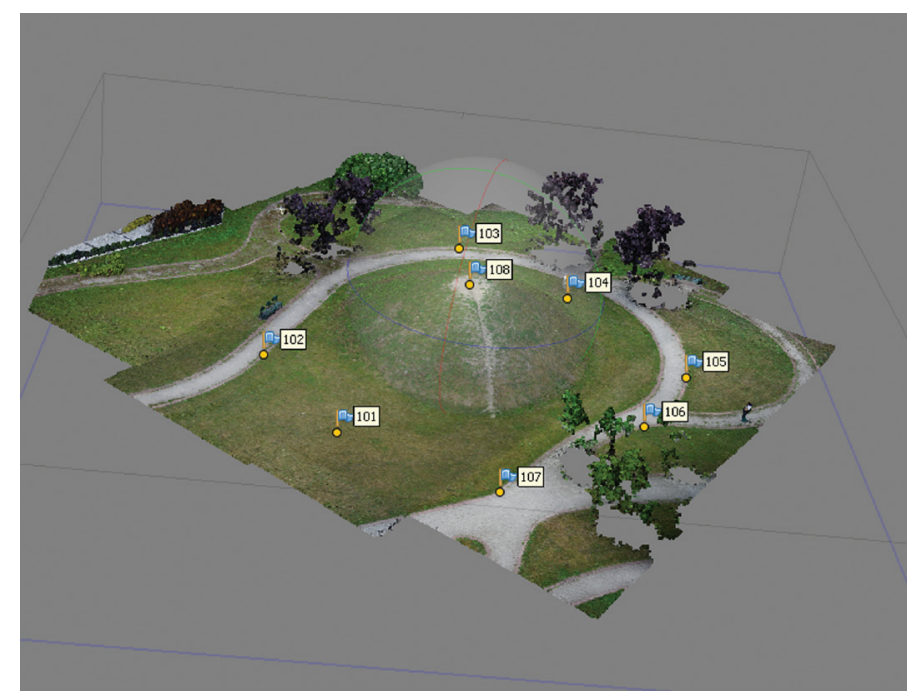

Fig. 8. View of a dense point cloud

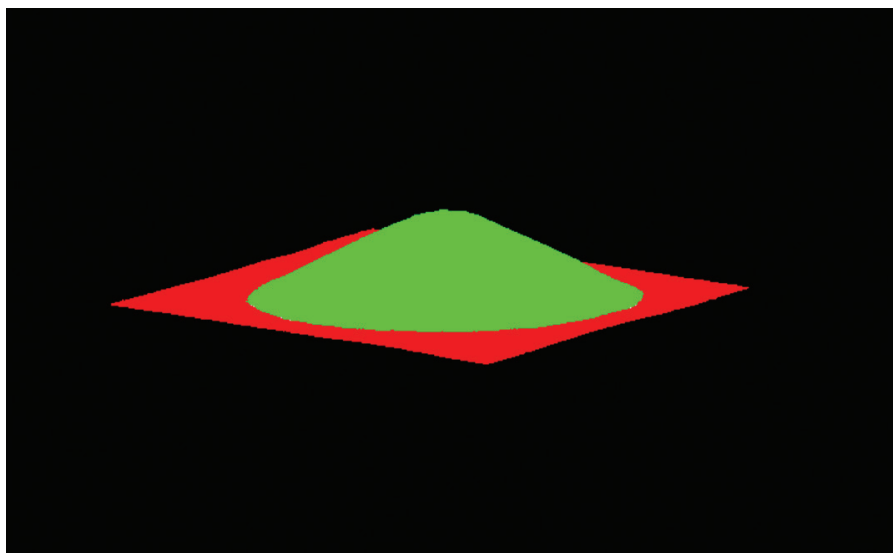

Fig. 9. Point cloud with two new MODELup classes (green), MODELdown (red) 


\section{Summary}

As noted earlier, calculating the volume for different types of surfaces and materials is important for many branches of engineering sciences. Correct volume calculation often has a significant impact on the costs and time needed to realise a given project. They are often used already at the design stage.

In the course of the research, the following results were obtained from different methods presented in the previous chapters (Table 1).

Table 1. A summary of the calculated volumes along with the approximate number of points

\begin{tabular}{|l|c|c|}
\hline \multicolumn{1}{|c|}{ Method of measurement } & Calculated volume $\left[\mathrm{m}^{3}\right]$ & Points no. \\
\hline terrestrial laser scanning & 486.9 & approx. 357 388 260 \\
\hline airborne laser scanning & 487.9 & 4392 \\
\hline UAV raid & 498.2 & 2845620 \\
\hline GNNS-RTK & 503.4 & 121 \\
\hline
\end{tabular}

The obtained results of calculations of the cubic capacity of soil masses differ depending on the methods used, which is a normal as it results from different ways of visualising the volume in 3D space, used in engineering calculations [Paleczek 2013]. The differences with respect to the assumed 'reference' volume were therefore calculated.

The volume from terrestrial laser scanning was considered to be the reference quantity as it has by far the highest number of points and accuracy. The advantage of this and the next two methods (presented in Tab. 1) is a significant reduction of errors resulting from poor selection of points, unfortunately occurring in the GNSS - RTK method. Thus, the results from the other three methods were compared to the terrestrial laser scanning method and the differences were calculated and listed in Table 2.

Table 2. Volume differences with respect to terrestrial scanning method

\begin{tabular}{|l|c|c|}
\hline \multicolumn{1}{|c|}{ Method of measurement } & Volume difference $\left[\mathrm{m}^{3}\right]$ & Volume difference $[\mathrm{m} 3]$ \\
\hline airborne laser scanning & 1.0 & 0.2 \\
\hline UAV raid & 11.3 & 2.4 \\
\hline GNNS-RTK & 16.5 & 3.4 \\
\hline
\end{tabular}

The relative volume error $\delta_{V}$ was also calculated, in accordance with the [Regulation of the Minister of the Environment of 28 October 2015], which is calculated according to formulas (1a) or (1b):

$$
\left|\delta_{V}\right|=\left|\left(V_{W}-V_{O}\right) / V_{W}\right|
$$


where:

$$
\left|\delta_{V}\right|=\left|\left(V_{W}-V_{O}\right) / V_{W}\right| \cdot 100[\%]
$$

$V_{w}$ - reference volume ('standard' volume),

$V_{o}$ - calculated volume.

The values of the errors received are listed in Table 3.

Table 3. Summary of the results of relative errors of the obtained values at the set limit values

\begin{tabular}{|l|c|c|c|c|}
\hline \multicolumn{1}{|c|}{ Method of measurement } & $V_{o}\left[\mathrm{~m}^{3}\right]$ & $V_{w}\left[\mathrm{~m}^{3}\right]$ & $\begin{array}{c}\delta \% \\
\text { calc. }\end{array}$ & $\begin{array}{c}\delta \% \\
\text { acc. }\end{array}$ \\
\hline airborne laser scanning & 487.9 & 486.9 & 0.2 & 4 \\
\hline UAV raid & 498.2 & 486.9 & 2.3 & 4 \\
\hline GNNS-RTK & 503.4 & 486.9 & 3.4 & 4 \\
\hline
\end{tabular}

The obtained results should be referred to the Regulation of the Minister of the Environment of 28 October 2015 on the surveying and geological documentation, where in part VI in the point 6.10.1 it is written:

The relative error of measuring the volume of overlayer dumping grounds and excavated storage sites must not exceed, for volumes:

1) up to 20 thou. $\mathrm{m}^{3}-4 \%$ of the volume,

2) more than 20 to 50 thou. $\mathrm{m}^{3}-3 \%$ of the volume,

2) more than 50 to 200 thou. $\mathrm{m}^{3}-2 \%$ of the volume,

4) more than 200 thou. $\mathrm{m}^{3}-1 \%$ of the volume.

Comparing the obtained results to the values presented in the Regulation, it can be concluded that the above calculations remain within the standards and have been performed correctly, and each of the measurement techniques presented above can be applied. However, the highest divergences in the measurements carried out are shown by the GNNS-RTK method, which may result from poor selection of points or from irregularities in the adopted reference level.

The use of RTK GPS techniques and total stations for determining the volume of soil masses is common. There are many computer programs at the disposal of a surveyor both universal geodetic applications and those dedicated specifically to a given device and measurement method. Creating a digital terrain model (DTM) with discontinuity lines, as well as the ability to automate the process of combining pickets with the same coding, measured consecutively, is undoubtedly an advantage of the programs used in this method [Poręba 2009].

The best results are achieved, when the laser scanning method is used to determine the volume of soil masses, regardless of whether it is terrestrial or airborne scanning, which proves that this method is the most accurate. However, the UAV is not far from it and, more importantly, its results are within the allowed standard limits. 
The presented methods were also compared in terms of time they require. Table 4 includes time statistics (approximate) that were needed in field work and calculations.

Table 4. Statistics of the total time taken by the measurement methods in question

\begin{tabular}{|c|c|c|c|c|c|}
\hline \multirow{2}{*}{$\begin{array}{c}\text { Method of } \\
\text { measurement }\end{array}$} & \multicolumn{2}{|l|}{ Fieldwork } & \multicolumn{2}{|l|}{ Desk study } & \multirow{2}{*}{$\begin{array}{l}\text { Total time } \\
{[\text { min }]}\end{array}$} \\
\hline & type of work & $\begin{array}{l}\text { time } \\
{[\mathrm{min}]}\end{array}$ & type of work & $\begin{array}{l}\text { time } \\
\text { [min] }\end{array}$ & \\
\hline $\begin{array}{l}\text { terrestrial } \\
\text { laser } \\
\text { scanning }\end{array}$ & $\begin{array}{ll}\text { - } & \text { scanning, } \\
\text { - } & \text { network } \\
& \text { measurement }\end{array}$ & $\begin{array}{l}90 \\
15\end{array}$ & $\begin{array}{l}\text { - scan orientation, } \\
\text { - cloud cleaning, } \\
\text { - calculations in Leica Cyclon }\end{array}$ & $\begin{array}{r}120 \\
30 \\
15\end{array}$ & 270 \\
\hline $\begin{array}{l}\text { airborne laser } \\
\text { scanning }\end{array}$ & $\begin{array}{l}\text { data obtained from } \\
\text { GUGiK }\end{array}$ & - & $\begin{array}{l}\text { - cutting the cloud and its } \\
\text { classification, } \\
\text { - calculations in Terrasolid }\end{array}$ & $\begin{array}{l}30 \\
10\end{array}$ & 40 \\
\hline UAV raid & 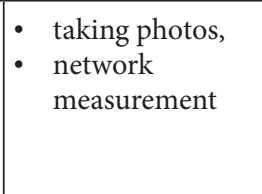 & $\begin{array}{l}10 \\
15\end{array}$ & $\begin{array}{l}\text { - alignment of the photo } \\
\text { block, } \\
\text { - cleaning and export of the } \\
\text { cloud, } \\
\text { - calculations in Terrasolid }\end{array}$ & $\begin{array}{l}45 \\
30 \\
10\end{array}$ & 110 \\
\hline GNNS-RTK & $\begin{array}{ll}\text { - } & \text { measurement at } \\
\text { points, } \\
\text { network } \\
\text { measurement }\end{array}$ & $\begin{array}{r}130 \\
15\end{array}$ & $\begin{array}{l}\text { - connection of points, } \\
\text { - calculations in C-GEO }\end{array}$ & $\begin{array}{l}30 \\
10\end{array}$ & 185 \\
\hline
\end{tabular}

Analysing the above table, it can be seen that in the case of the examined object (mound), the least time-consuming measurement method turned out to be the aerial laser scanning. This was due to the fact that data in the form of a point cloud was obtained from GUGiK, there was no need to conduct field work, and the point cloud was processed in the TerraSolid program, which enables automatic classification of points and quick calculation of the cubic capacity of objects.

Obtaining and processing data with the terrestrial laser scanning method took the most time, which was caused by the high precision of scanning and additional shooting with the camera built into the scanner. On the other hand, processing such a huge amount of data in Leica Cyclon required orientation of the point cloud and its thorough cleaning from noise. For the other two methods, the UAV method proved to be less time-consuming.

In summary, the use of each of the demonstrated methods appears to be reasonable and may depend largely on site characteristics and the time required to compile the data. Methods based on scanning and UAV may prove to be more advantageous in more difficult terrain, where a surveyor who wants to take measurements with a GNSS receiver could not reach or in areas lush with vegetation. The advantages of methods performed from the air (LIDAR and drone) are the ability to obtain data for large areas. The advantage of receiver measurement is the speed of measurement, lower dependence on weather conditions and the speed of data processing. 
Financed by a subsidy from the Ministry of Education and Science for the University of Agriculture in Kraków for 2021.

\section{References}

Barbarella M., Fiani M., Lugli A. 2015. Landslide monitoring using multitemporal terrestrial laser scanning for ground displacement analysis. Geomatics Natural Hazards Risk, 6 (5-7), 398-418. https://doi.org/10.1080/19475705.2013.863808.

Eisenbeiss H., Sauerbier M. 2011. Investigation of UAV systems and flight modes for photogrammetric applications. Photogramm. Rec., 26, 400-421. https://doi.org/10.1111/j.14779730.2011.00657.x.

Figueira N.M., Freire I.L., Trindade O., Simoes E. 2015. Mission-oriented sensor arrays and UAVs. A case study on environmental monitoring. ISPRS Int. Arch. Photogramm. Remote Sens. Spat Inf. Sci., 305-312, XL-1/W4.

Janowski A., Jurkowska A., Lewczuk D., Szulwic J., Zaradny A. 2014. Assessment of cliff stability after the demolition of the engineering facilities. 14th SGEM GeoConference on Science and Technologies in Geology, Exploration and Mining, 115-124. doi:10.5593/SGEM2014/ B12/S2.016.

Kenner R., Bühler Y., Delaloye R., Ginzler C., Phillips M. 2014. Monitoring of high alpine mass movements combining laser scanning with digital airborne photogrammetry. Geomorphology, 206, 492-504.

Klapa P., Mitka B. 2017. Application of terrestrial laser scanning to the development and updating of the base map. Geodesy Cartography, 66 (1), 59-72. https://doi.org/10.1515/geocart-2017-0002.

Kociuba W., Kubisz W., Zagórski P. 2014. Use of Terrestrial Laser Scanning (TLS) for monitoring and modelling of geomorphic processes and phenomena at a small and medium spatial scale in Polar environment (Scott River - Spitsbergen). Geomorphology, 212, 84-96.

Kwinta A., Szeptalin A. 2010. Wykorzystanie ręcznych odbiorników GNSS do pomiarów powierzchni działek rolnych. Infrastruktura i Ekologia Terenów Wiejskich, 6. Polska Akademia Nauk, 157-166.

McGonigle A.J.S., Aiuppa A., Giudice G., Tamburello G., Hodson A.J., Gurrieri S. 2008. Unmanned aerial vehicle measurements of volcanic carbon dioxide fluxes. Geophys. Res. Lett., 35, L06303. https://doi.org/10.1029/2007GL032508.

Mitka B., Klapa P., Piech I. 2018. Comparative analysis of geospatial data received by TLS and UAV technologies for the quarry. 18th International Multidisciplinary Scientific GeoConference SGEM2018: Conference Proceedings, 18: Informatics, Geoinformatics and Remote Sensing, 2.3: Photogrammetry and Remote Sensing, Cartography and GIS, International Multidisciplinary Scientific GeoConference \& EXPO SGEM, 18, 2.3. Sofia, SGEM, 57-64, doi:10.5593/sgem2018/2.3/S10.008

Paleczek W. 2004. Metody analizy danych na przykładach. Wydawnictwo Politechniki Częstochowskiej, Częstochowa.

Paleczek W. 2013. Analiza dokładności obliczania objętości mas ziemnych. Budownictwo, 21, 365-371.

Pilecki R. 2012. Zastosowanie naziemnego skanera laserowego. Mechanika. Czasopismo Techniczne. Wyd. Politechniki Krakowskiej, 9-M, 26, 223-233.

Poręba M. 2009. Nowoczesne metody pomiarów mas ziemnych. Archiwum Fotogrametrii, Kartografii i Teledetekcji. AGH, Kraków. 
Quintero M.S., Garcia J.L.L., Genechten B.V. 2008. 3D Risk Mapping Theory and Practice on Terrestrial Laser Scanning. Training Material Based on Practical Applications. Universidad Politecnica de Valencia, Valencia, Spain.

Raeva P.L., Filipova S.L., Filipov D.G. 2016. Volume computation of a stockpile. A study case comparing GPS and UAV measurements in an open pit quarry. Int. Arch. Photogramm. Remote Sens. Spat. Inf. Sci., 41, 999-1004.

Rozporządzenia Ministra Środowiska z dnia 28 października 2015 roku w sprawie dokumentacji mierniczo-geologicznej. Dz.U. 2015 poz. 1941.

Shahbazi M., Sohn G., Théau J., Menard P. 2015. Development and evaluation of a UAV-photogrammetry system for precise 3D environmental modelling. Sensors, 15, 27493-27524.

Tang Z., Dong X., Yang Y., Ma L. 2014. Research on the relationship between grain composition and repose angle of coal gangue in Dongkuang mine, Heshan city, Guangxi, China. J. Earth Sci., 25(2), 309-314.

Tang S., Lu X., Zheng Z. 2013. Platform and state estimation design of a small-scale UAV helicopter system. Int. J. Aerospace Eng., 524856.

Wężyk P. 2006. Wprowadzenie do technologii skaningu laserowego w leśnictwie. Polskie Towarzystwo Informacji Przestrzennej, IV, 4. Roczniki Geomatyki, 120-126.

Wójcik A., Klapa P., Mitka B., Piech I. 2019. The use of TLS and UAV methods for measurement of the repose angle of granular materials in terrain conditions. Measurement, 146, 780-791.

Xiang J., Chen J., Sofia G., Tian Y., Tarolli P. 2018. Open-pit mine geomorphic changes analysis using multi-temporal UAV survey. Environ. Earth Sci., 77 (220), 1-18.

Xu Y., Sun W., Li P. 2014. A miniature integrated navigation system for rotary-wing unmanned aerial vehicles. Int. J. Aerospace Eng., 748940.

Dr inż. Bogusława Kwoczyńska

University of Agriculture in Krakow

Department of Agricultural Land Surveying, Cadastre and Photogrammetry

ul. Balicka 253a, 30-198 Kraków

e-mail: boguslawa.kwoczynska@urk.edu.pl

ORCID: 0000-0001-7230-5397 